\title{
Learn to Defend Your Family Firm
}

\author{
Franz Kellermanns (UNC - Charlotte \& WHU) \\ Nadine Kammerlander (WHU - Otto Beisheim School of Management)
}

KEYWORDS: Entrepreneurship, Innovation, Family Business.

While the world around them is changing at a faster and faster pace in the midst of uncertainty, family firms are often a beacon of stability and dependability in our society. Although subject to the same external and environmental pressures as other firms, family firms, due to their long and rich history and their values, are sometimes resistant to change. Accordingly, family firms need to identify changes in the environment and the potential consequences of these changes. This classroom exercise helps students who will be part of a family business to anticipate external challenges, adjust business strategies accordingly and defend their family firm.

Note: This can be made into a general entrepreneurial exercise by replacing its focus on a "family firm" with other firms being studied and discussed in class. This, however, requires job experience and may work best with MBA students

\section{The Exercise}

This exercise works best in classes/modules where the participants are predominantly from family firms. The class splits up into smaller groups (see notes below) of 3-5, ensuring that at least one family firm is represented in each group. Each student from a family firm can have a turn being the focal business of the group exercise, or the instructor can choose to have only one family business serve as the focal business per group.

If students did not have exposure to business models, Exhibit 1 (see Appendix) can be used as a general introduction to the topic by the instructor. Exhibit 2 (see Appendix) introduces the students to different types of uncertainty and help generate higher quality discussion.

The student with a family business then explains the firm's current business model. A business model describes how a company plans to generate sales and make a profit. As such it explains the product or

services of the company, but also includes an understanding of the major cost drivers of the business and of the assumptions that need to met (e.g., regarding customer behavior etc.) to make the family firm successful. Basically, a business model explains how the business works. (As a pre-assignment, students from a family business with limited work experience could ask the owners of their business to explain the business model to them.) The other group members then should discuss how the business model could fail as the environment changes. They should approach this discussion from the point of view of a new venture that wants to challenge the family firm. As a new venture, their approach to the product and services offered by the family firm is not bound by (historical) constraints or assumptions. As a last step, all group members can work on the "defense" of the family firm and develop strategies for the family firm to address environmental changes. Exhibit 3 (see Appendix) introduces the exercise to the students.

Team Size: There is no required team size. In the case of predominantly family firm members in the course, the group size needs to be small to avoid overly lengthy discussion. The minimum team size is two (one person presents the current business model and the other challenges it). With a limited number of family firms, the teams should be structured so each group has at least one family firm member who can defend the business model, with the other students trying to destroy it.

\section{Timing}

The entire exercise can last 50-75 minutes depending on class dynamics and key learning outcomes discussed by the instructor. The exercise generally goes beyond 50 minutes if more than one group member wants to present his/her firm's current business model. The initial explanation of each family firm's business model should take about $5-10$ minutes, allowing more time if the class consists of predominantly family firm
Copyright ( 2018 The Authors. Entrepreneur \& Innovation Exchange is published at EIX.org. This is an open access article under the terms of the Creative Commons Attribution-NoDerivs License, which permits use and distribution in any medium, provided the original work is properly cited and no modifications or adaptations are made. View EIX.org Authorship Terms at https://eix.org/terms
FamilyBusiness 
members. Depending on participant experience and education, a brief introduction of business model and environmental uncertainty (Exhibits 1-2 in the Appendix) can be useful. In addition, it can be beneficial to discuss disruption and how disruptions are triggered (e.g., technological breakthroughs, regulatory or political changes, shifting customer demands, etc.) or how they typically evolve (e.g., the model of punctuated equilibrium of Anderson and Tushman or the disruption theory of Clayton Christensen) (10 minutes - optional).

The students then break into small groups and discuss the creative destruction of the business model and the potential steps the family firm should take to address the changes in the environment, as well as the other discussion questions (see Exhibit 3 in the Appendix). This should take between 30-45 minutes. More specifically, after the family firm participant briefly explains his/her current business model and answers any questions from group members, the group members start asking "what if" questions, building future scenarios in which their startup could destroy the foundation of the family firm's business model. During this discussion, the family firm participant is encouraged to defend his/her business model. The session closes with short debriefing questions to share knowledge and summarize takeaways (15 minutes). Exhibit 4 and 5 (see Appendix) can help guide this discussion.

\section{Discussion and Debriefing Questions}

The exercise introduces the notion of environmental change, business models and path dependency of family firms vs. start-ups. Below are a few debriefing questions, which are also summarized in Exhibit 4 in the Appendix.

1. What type of uncertainty do you currently face in your environment? What uncertainties do you expect in future? What are potential (e.g., technological, political) drivers of such uncertainties?

We recommend the following article:

Schoemaker, P. J. H. 1995. Scenario planning: a tool for strategic thinking. Sloan Management review, 36(2): 25-40.

2. Your team members came up with ways to destroy your business model. Does your firm see it coming? Why or why not? What needs to happen so that your business model does not get destroyed and remains viable?

3. How is a family firm unique in reacting to changes in the environment? What key capabilities of your family firm will endure in spite of disruption?

4. Is it easier to defend/improve on your current business model or to approach the problem from scratch? What are the advantages and disadvantages of each?

\section{Key Learning Outcomes What did they learn?}

Students gain a stronger foundation in at least three areas. First, they learn about the interplay of the various elements of business models. In particular, they gain a better understanding of how vulnerable today's business models are and how easily potential (future) changes in the environment can destroy models that have been effective for decades. Second, students learn about the complexity of family businesses and about the delicate balance of maintaining tradition yet being entrepreneurial. The discussions aimed at destroying the established business model and the family firm member who defends the established business model vividly illustrate path dependency. Third, the exercise highlights the importance of out-of-the-box thinking and scenario planning. By asking creative "but what if" questions, team members challenge the family firm participant's thinking and beliefs. Students learn about the importance of asking the right questions in a systematic way and of finding answers/potential reactions to a variety of possible future scenarios. In particular, they learn how combining strategic reasoning with creative brainstorming might lead to solutions for the future of their business.

\section{Key takeaways of participants:}

- Disruption happens not only to others but also to every (family) business.

- Business models are not static; they can be continuously challenged and updated when required.

- Even in seemingly stable environments like a family business, maintaining an entrepreneurial spirit is an important driver of future success.

- Globalization and digitalization have the 
potential to disrupt many industries -- if not today, then in the future.

- "What if" questions and systematic scenario planning can reduce uncertainty, complexity and ambiguity, thus helping to ensure the firm's viability for the future.

- A dialogue that includes the incumbent perspective as well as a start-up perspectives is very fruitful for discussion.

- Next-generation members can add real value to the family firm by recognizing potential trends and technological developments, thus foreseeing future disruptions. In this regard, what potential value could you bring to your family's firm?

\section{Appendix: PowerPoints Exhibit 1: Business Model}

Business model: A business model describes the rationale of how an organization creates, delivers and captures value in economic, social, cultural or other contexts. The process of business model construction and modification, also called business model innovation, forms a part of business strategy. (Wikipedia.com)

It has two related dimensions:

- How are you generating income (economic logic)?

- What are the key assumptions of the business -key customers, what customers value, how value can be delivered to the customer (cost, production, logistics, etc.?)

\section{Exhibit 2: Types of Uncertainty Based on Schoemaker (1995)}

- Uncertain situations are full of new opportunities.

- Your task is to continuously identify highpotential business opportunities and exploit these opportunities with speed and confidence.

- Uncertainty can become your ally, not your enemy.

- Three types of uncertainty:

- A clear-enough future

- Alternative futures
- A range of futures
- True ambiguity

\section{Exhibit 3: Exercise}

Form small groups with at least one person from a family business.

1. Take 5-10 minutes to explain your family firm's business model to the group. Describe the following elements of your business model to your fellow students:

2. In what areas is your business active? Focus on the main area.

- How does your business model work -- i.e., how do you generate income?

- Who are your customers and how do you generate value for them? What are key costs in your business?

- What is your competitive advantage? What makes your business successful today?

- What are the key assumptions that your business holds?

3. Consider that the remainder of your group is starting a new venture. What chances do you see to destroy the business model of the established family firm? How would you attack their business model? Consider why the business model would not work in the future. Identify key dangers to the business model. (10-15 minutes)

4. Discuss what would have to happen for these scenarios to occur. What can the family firm do to prevent it? (10-15 minutes)

5. As a potential success of the family business, will the business model be attractive to the next generation (5 minutes)?

6. General class discussion, with each group sharing their main insights. (15-20 minutes)

\section{Exhibit 4: Discussion and Debriefing Questions}

1. What type of uncertainty do you currently face in your environment? What uncertainties do you expect in future? What are potential (e.g., 
technological, political) drivers of such uncertainties?

2. Your team members came up with ways to destroy your business model. Does your firm see it coming? Why or why not? What needs to happen so that your business model does not get destroyed and remains viable?

3. How is a family firm unique in reacting to changes in the environment? What key capabilities of your family firm will endure in spite of disruption?

4. Is it easier to defend/improve on your current business model or to approach the problem from scratch? What are the advantages and disadvantages of each?

\section{Exhibit 5: Family Firm - Path Dependency}

Why do family firms behave in a certain way, despite the presence of alternatives?

- Role of family firm founder

- Role of family firm culture

- Role of the family's history

- Pursuit of socio-emotional wealth

- Role of governance

- Role of long-tenured employees and loyal customers

- Role of family patriarchs/matriarchs

- Geographic influences

Additional Search Terms: entrepreneurship courses, teaching ideas, teaching resources, classroom ideas, entrepreneurship classes, business schools, business school classes, entrepreneurship students, professors 